$\mathrm{NF}=180.5 \mathrm{pg} / \mathrm{ml}$ vs FF $332.0 \mathrm{pg} / \mathrm{ml}, \mathrm{p}=0.0012)$ by ELISA and confirmed by WB. Furthermore, increased $\mathrm{VEGF}_{165} \mathrm{~b}$ protein expression was also observed in FF by WB. Recombinant VEGF $_{165} \mathrm{~b}$ had no effect on fibronectin or $\alpha$-SMA expression in $\mathrm{NF}$, but $\mathrm{VEGF}_{165}$ a $(10 \mathrm{ng} / \mu \mathrm{l})$ significantly increased expression of fibronectin $(\mathrm{p}<0.05)$. Interestingly, co-administration of VEGF $_{165}$ a with $V_{E G F}{ }_{165} \mathrm{~b}$ inhibited both $\alpha$-SMA and fibronectin expression in these cells (Figure 1).

Conclusion Differential expression of VEGF isoforms between $\mathrm{NF}$ and FF suggests a potential role in the development of IPF. Furthermore, results suggest that factors altering the balance of splice variants may influence the surrounding fibrotic milieu.

Effect of rhVEGF 165 a + rhVEGF$_{165}$ b on fibronectin and $\alpha$-SMA expression in normal fibroblasts

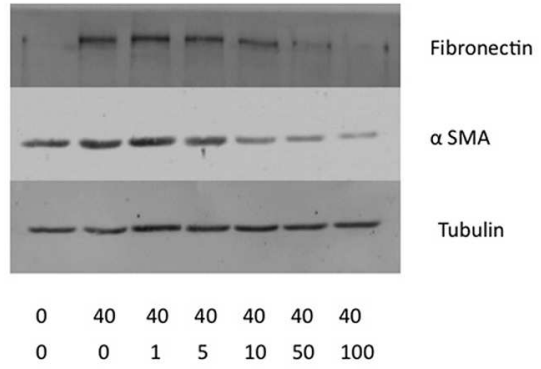

Abstract P141 Figure 1.

\section{P142 SRC KINASE INHIBITION ATTENUATES NEUTROPHIL DEGRANULATION WITHOUT IMPAIRING BACTERIAL KILLING: A POSSIBLE THERAPEUTIC STRATEGY FOR ACUTE LUNG INJURY?}

JG Macfarlane, MH Ruchaud-Sparagano, JA Scott, DA Bulmer, CMA Khan, AJ Simpson; Newcastle University, Newcastle upon Tyne, UK

\subsection{6/thoraxjnl-2013-204457.292}

Background A key mechanism in the pathogenesis of acute lung injury (ALI) is excessive neutrophil degranulation in response to an overwhelming inflammatory or infective insult. To date, no pharmacological therapy for ALI has proven beneficial.

Aim To investigate our hypothesis that extracellular neutrophil degranulation can be inhibited without necessarily impairing phagocytosis or live bacterial killing.

Methods Whole blood or purified neutrophils from healthy volunteers were pre-treated with a src kinase inhibitor (PP1) or vehicle control, before stimulation with either Phorbol 12-myristate 13-acetate (PMA), cytochalasin B + N-formylmethionylleucyl-phenylalanine (fMLP), lipopolysaccharide (LPS), live serum-opsonized Staphylococcus aureus (SA) or Pseudomonas aeruginosa (PA), to induce degranulation. Degranulation was measured in whole blood using CD63/CD66b expression and in purified neutrophils by extracellular release of myeloperoxidase (MPO) and lactoferrin (LTF). Neutrophil phagocytosis of fluorescent killed bacteria, cell viability, apoptosis and bacterial killing (by serial dilution and colony counting) were also measured. All experiments carried out using $n=4-6$ healthy volunteers.

Results PP1 pre-treatment using concentrations above $10 \mu \mathrm{M}$ significantly attenuated primary and secondary granule exocytosis from healthy neutrophils in response to LPS, cytochalasin B/ fMLP, SA and PA but not to PMA. The same effect was observed in whole blood assays and in purified neutrophils, both in free suspension and when adhered to tissue culture plastic. PP1 treatment did not increase neutrophil death in response to the stimuli, nor did it significantly alter baseline apoptosis rates. Importantly, PP1 did not impair neutrophil phagocytosis or live bacterial killing of SA and PA.

Conclusions Our study supports our hypothesis and proposes src kinases as an attractive target for anti-inflammatory therapy in conditions such as ALI.

\section{P143 HYPOXIA INDUCES HYPOTHERMIA AND SICKNESS BEHAVIOUR IN MICE FOLLOWING SUBCUTANEOUS INJECTION OF LIVE STAPHYLOCOCCUS AUREUS}

${ }^{1} \mathrm{AAR}$ Thompson, ${ }^{1} \mathrm{HM}$ Marriott, 'L Williams, ${ }^{1} \mathrm{G}$ Shaw, ${ }^{1} \mathrm{~A}$ Hameed, 'S Parmar, ${ }^{1} \mathrm{~J} A$ Preston, ${ }^{2} \mathrm{MC}$ Simon, ${ }^{1} \mathrm{RS}$ Johnson, ${ }^{1} \mathrm{SJ}$ Foster, ${ }^{1} \mathrm{DH}$ Dockrell, ${ }^{1} \mathrm{MK}$ Whyte, ${ }^{1} \mathrm{SR}$ Walmsley; ${ }^{1}$ University of Sheffield, Sheffield, UK; ${ }^{2}$ University of Pennsylvania, Philadelphia, USA

\subsection{6/thoraxjnl-2013-204457.293}

Infections frequently cause or complicate illnesses associated with hypoxaemia and local tissue hypoxia. The influence of hypoxia on the interaction between host and pathogen is therefore of considerable interest. $S$. aureus is a major pathogen in critical care where patients may have profound hypoxaemia and at a tissue level, $S$. aureus frequently infects ischaemic wounds. We investigated the effect of systemic hypoxia on host-pathogen interactions using a subcutaneous $S$. aureus infection model in mice.

C57BL/6 mice were shaved, injected with a low dose of $S$. aureus $\left(5 \times 10^{7} \mathrm{SH} 1000\right)$ and placed in a hypoxic chamber $(10 \%$ $\mathrm{O}_{2}$ ) or left in room air. At 6 or 12 hours mice were assessed clinically and rectal temperature recorded. Clinical assessment of mouse sickness behaviour was made by two independent observers blinded as to which oxygen tension the mice had been exposed. Mice were anaesthetised and tissue samples (blood, skin, lung, spleen, kidney, liver and brain) obtained for analysis.

Mice injected with live bacteria and placed in hypoxia developed a phenotype of sickness behaviour and hypothermia. Infected hypoxic mice had significantly higher sickness scores and lower body temperature than infected normoxic mice or hypoxic mice injected with PBS (rectal temperature at 12 hours: hypoxic $33.4^{\circ} \mathrm{C} \pm 0.74$, normoxic $37.7^{\circ} \mathrm{C} \pm 0.24$, hypoxic PBS-injected $\left.38.9^{\circ} \mathrm{C} \pm 0.26, \mathrm{p}<0.0001\right)$. Surprisingly, we found no evidence of bacteraemia, enhanced cytokine production, vascular leak or lung injury in the hypoxic infected mice. However, these animals had significant circulatory dysfunction, with hypotension, bradycardia and echocardiographic evidence of impaired left ventricular function. Interestingly, myeloid-cell deficiency of either HIF- $1 \alpha$ or HIF- $2 \alpha$ protected mice from the adverse systemic phenotype in this model, implicating the host innate immune response in the pathogenesis of the phenotype.

These findings imply that hypoxia may adversely alter the host response to a minor bacterial challenge, leading to profound systemic illness and that in such a setting modulation of the HIF pathway may be a possible therapeutic option.

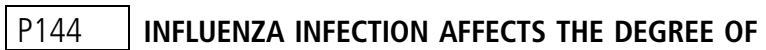 FIBROSIS AND APOPTOSIS IN THE BLEOMYCIN MOUSE MODEL}

A Stavrou', L Jolly', A Habgood', A John', T Hussel', A Blanchard ${ }^{3}$, G Jenkins'.; ${ }^{1}$ University of Nottingham, Nottingham, UK; ${ }^{2}$ Imperial College London, London, UK; ${ }^{3}$ GSK, Stevenage, UK

10.1136/thoraxjnl-2013-204457.294 